\title{
"Conheço bem mais uma arte do outro lado do mundo que uma aqui do outro lado do rio": luta Marajoara e reconhecimento em academias de ginástica
}

\author{
"I know more about an art on the other side of the world than one here across the river": \\ Marajoara Fight and recognition in fitness centers
}

"Sé más sobre un arte del otro lado del mundo que aquí del otro lado de río": lucha Marajoara y reconocimiento en gimnasios

Carlos Afonso Ferreira dos Santos, Welison Alan Gonçalves Andrade ${ }^{\mathrm{II}}$, Rogério Gonçalves de Freitas ${ }^{\mathrm{III}}$

\begin{abstract}
Resumo
O objetivo da pesquisa foi compreender como a lógica de funcionamento de academias de ginástica de Belém-PA (Brasil) influencia no reconhecimento e oferta da prática da Luta Marajoara. Constitui-se de pesquisa qualitativa com dados obtidos a partir de entrevistas semiestruturadas com professores de lutas e coordenadores de academias. Constatou-se ausência da prática da Luta Marajoara no espaço das academias investigadas e conclui-se que a condição para seleção das modalidades de lutas depende exclusivamente da demanda oriunda dos clientes, legitimando, portanto, o não reconhecimento da Luta Marajoara nas academias de ginástica. Outra conclusão foi a de que o mercado esportivo é um sistema determinante para o "gosto" de práticas de lutas mais reconhecidas que a Luta Marajoara, contribuindo para o esquecimento desta modalidade de luta autenticamente brasileira.
\end{abstract}

Palavras-chave: Educação física; Luta Marajoara; Academia de ginástica; Gosto social

\begin{abstract}
The research aimed to understand how the logic of functioning of fitness centers in Belém (Pará State/Brazil) influences the recognition and offer of the practice of Marajoara Fight. It was a qualitative research with data obtained from semi-structured interviews with fighting teachers and fitness centers managers. As a result, there was an absence of the practice of Marajoara Fight in the space of the investigated fitness centers and it is concluded that the condition for selecting the types of fights depends exclusively on the demand from customers, thus legitimizing the non-recognition of Marajoara Fight in fitness centers. Another conclusion was that the sports market is decisive for the "taste" of fighting practices more recognized than the Marajoara Fight, contributing to the oblivion of this authentically Brazilian fighting modality.
\end{abstract}

Keywords: Physical Education; Marajoara fight; Fitness centers; Social taste

\footnotetext{
${ }^{\text {I } U n i v e r s i d a d e ~ F e d e r a l ~ d o ~ P a r a ́ ~-~ U F P A ~-~ E n d e r e c ̧ o: ~ R . ~ A u g u s t o ~ C o r r e ̂ a, ~} 01$ - Guamá, Belém - PA, CEP: 66075-110, Brasil - e-mail: afonso.fersantos@gmail.com

II Universidade Federal do Pará - UFPA - e-mail: andradewalan@gmail.com

${ }^{\text {III }}$ River East Transcona School Division - Retsd - e-mail: rgoncalvesdefreitas@ retsd.mb.ca
} 


\section{Resumen}

El objetivo de la investigación fue comprender cómo la lógica de funcionamiento de los gimnasios en Belém, estado de Pará (Brasil) influye en el reconocimiento y oferta de la práctica de Lucha Marajoara. Consiste en una investigación cualitativa con datos obtenidos de entrevistas semiestructuradas con profesores de lucha y coordinadores de gimnasios. Se constató que no hubo práctica de Lucha Marajoara en el espacio de los gimnasios investigados y se concluyó que la condición para seleccionar las modalidades de combate depende exclusivamente de la demanda proveniente de los clientes, legitimando, por tanto, el no reconocimiento de la Lucha Marajoara en los gimnasios. Otra conclusión fue que el mercado deportivo es determinante para el "gusto" de prácticas de lucha más reconocidas que la Lucha Marajoara, contribuyendo al olvido de esta modalidad de lucha auténticamente brasileña.

Palabras clave: Educación Física; Lucha Marajoara; Gimnasio; Gusto social

\section{Introdução}

Luta Marajoara é uma prática corporal genuinamente brasileira, assim como o Huka-huka e a Capoeira. Gestualidade e técnica são alguns de seus aspectos culturais e representam símbolos de sua territorialidade: o arquipélago do Marajó, situado no norte do Brasil.

Pouco conhecida nacionalmente, a Luta Marajoara parece ser esquecida mesmo no interior das fronteiras de seu estado de origem. No âmbito educacional paraense, de acordo com documentos oficiais (currículo e Projeto Político Pedagógico) e escolas marajoaras, a referida luta não possui lugar demarcado na formação docente em Educação Física (SANTOS; GOMES; FREITAS, 2020), tampouco em instituições de educação básica (SANTOS; FREITAS, 2018). Realidade corrente mesmo com o fato da Luta Marajoara agregar aspectos semelhantes à de outras modalidades de lutas (CAMPOS; PINHEIRO; GOUVEIA, 2019) presentes na formação e nas práticas pedagógicas de professores de Educação Física.

Somada às investigações que objetivaram discutir a Luta Marajoara em espaços de relevância social e educativa no estado do Pará, esta pesquisa analisou sua presença ou ausência no âmbito de academias de ginástica da cidade de Belém. A pergunta norteadora da pesquisa foi definida como: a Luta Marajoara tem sua prática reconhecida, ofertada e difundida nas academias de ginástica de Belém-PA?

Apesar de seu caráter majoritariamente privado e viés comercial, as academias de ginástica atuam como espaço educativo dedicado à oferta e ao ensino de diferentes práticas corporais, como as lutas. Trata-se, portanto, de um contexto aparentemente ideal à disseminação e reconhecimento da Luta Marajoara.

Nessa perspectiva, as análises conduzidas por este artigo se basearam no processo de reconhecimento da identidade da Luta Marajoara em um lócus particular de convivência humana. Para isso, a teoria do reconhecimento de Charles Taylor (2000) pode ser uma chave de análise para 
compreender seu papel na formação de identidade. Para o autor, o reconhecimento desempenha, no cenário contemporâneo e democrático, um valor fundamental, e permite que determinados grupos sociais (nesse caso, determinadas práticas socioculturais, como a Luta Marajoara) construam suas identidades e, ao mesmo tempo, afastem-se de visões estereotipadas em relação a sua imagem na sociedade.

Para entender o reconhecimento da Luta Marajoara em academias de Belém-PA, há igualmente a necessidade de considerar fatores e influências que podem estar diretamente relacionados a esse fenômeno. Nesta pesquisa, destacou-se o fenômeno esportivo e seu papel frente ao capital (COLOMBO, 2014), bem como o conceito de gosto (BOURDIEU, 1983, 2007).

Com objetivo de compreender como a lógica de funcionamento de academias de ginástica de Belém-PA influencia no reconhecimento da prática de Luta Marajoara, a presente pesquisa conectou-se com estudos recentes (SANTOS; FREITAS, 2018; SANTOS; GOMES; FREITAS, 2020) que se propuseram a refletir sobre o reconhecimento que possui essa luta na escola e no currículo de formação docente no campo da Educação Física.

\section{Procedimentos metodológicos}

A pesquisa teve duas etapas metodológicas interdependentes. Na primeira, de caráter diagnóstico, realizou-se busca de informações referentes à oferta da Luta Marajoara em 30 academias de ginástica da cidade de Belém, capital do estado do Pará. A coleta se deu por meio de contato telefônico, acesso a páginas da web, redes sociais e troca de mensagens instantâneas, visando à construção de um universo quantitativo que retratasse a presença ou ausência dessa modalidade de luta.

Diagnosticada a ausência de oferta da Luta Marajoara em todas as academias, em função de fatores distintos, como demanda e desconhecimento da prática corporal, partiu-se para a segunda etapa metodológica, a qual se baseou nos dados da fase anterior, e buscou, em perspectiva qualitativa, entender os motivos associados à referida ausência.

Para tanto, duas das academias investigadas foram selecionadas; uma de grande porte e outra de pequeno porte. A escolha de academias de diferentes portes deveu-se ao fato de analisar realidades e públicos diferentes. Enquanto a primeira tem ampla variedade de atividades e atende público de maior poder aquisitivo, a segunda, localizada em bairro periférico, possui poucos funcionários e mensalidades mais acessíveis. "Grande porte" e "pequeno porte" referem-se aos nomes adotados neste artigo para as duas academias selecionadas. 
Foram selecionados como sujeitos da pesquisa dois coordenadores ${ }^{1}$ (um do sexo masculino e um do sexo feminino) e quatro professores ${ }^{2}$ de lutas (três do sexo masculino e um do sexo feminino). O Quadro 1 os identifica. As siglas de denominação dos professores se referem às iniciais das lutas com as quais trabalham; a mesma lógica reside nas iniciais dos coordenadores das academias.

Quadro 1 - identificação dos sujeitos.

\begin{tabular}{l|l|l}
\cline { 2 - 3 } & \multicolumn{1}{|c}{ Academia de "grande porte" } & \multicolumn{1}{c}{ Academia de "pequeno porte" } \\
\hline \multirow{2}{*}{ Professores } & S1 (Submission) & MT2 (Muay Thai) \\
& C1 (Capoeira) & JJ2 (Jiu-Jitsu) \\
\hline Coordenadores & CO1 (Coord. Academia 01) & CO2 (Coord. Academia 02) \\
\hline
\end{tabular}

Fonte: Os autores.

Cada professor é responsável por uma modalidade de luta. Na academia de grande porte, um professor atua com o Submission, além de Jiu-Jitsu, enquanto outra professora ministra Capoeira. Na de pequeno porte, um professor trabalha com o Muay Thai, enquanto o outro com o Jiu-Jitsu.

Para a coleta de dados, realizada no período de setembro de 2019 a novembro do mesmo ano, foram feitas entrevistas semiestruturadas. Segundo Gil (2008), a entrevista é uma técnica que possibilita a obtenção de dados suscetíveis à classificação. Optou-se, então, pela modalidade semiestruturada, em razão da possibilidade de se obter um apoio claro na sequência das questões, por meio de um roteiro apropriado fisicamente, e, assim, facilitar a abordagem (MINAYO, 2010).

As entrevistas permitiram, tanto aos professores de lutas quanto aos coordenadores, expressarem suas opiniões acerca da prática da Luta Marajoara nas academias de ginástica, localizadas na região norte do Brasil, lócus propício a sua prática e difusão.

A ida a campo considerou contato prévio com coordenadores das academias selecionadas para apresentação do objetivo da pesquisa e concessão de permissão para sua realização nesses espaços de natureza privada. Com vista a obter o consentimento em relação à participação no estudo, foi entregue aos sujeitos o Termo de Consentimento Livre e Esclarecido (TCLE). Sua aplicação permitiu situá-los quanto aos objetivos e procedimentos metodológicos adotados na pesquisa.

\footnotetext{
${ }^{1}$ Exercem funções administrativas relacionadas à organização das atividades desenvolvidas nas academias, no que se refere à composição de horários, contratação e lotação de profissionais, gestão do espaço físico e materiais, entre outras.

${ }^{2}$ Sujeitos contratados pelas academias e atuantes com as lutas e artes marciais.
} 


\section{Academias de ginástica e "gosto social"}

Segundo Furtado (2009), as academias de ginástica, ao longo de seu percurso histórico, passaram por mudanças nas características de organização, multiplicando a procura pelo serviço ofertado em seus espaços. Conforme o autor, as academias foram se transformando em empresas, imitando o modelo de acumulação flexível, com intuito fundamental de aumentar a velocidade de circulação do capital.

Novas modalidades de exercícios físicos ou práticas corporais representam, na concepção da academia como negócio lucrativo, novas e outras formas de produção de valor e mercadorias. Este aspecto é reforçado pela influência que determinadas atividades corporais - do esporte-espetáculo em expansão na sociedade - exercem na seleção feita por seus proprietários. Potencialmente atrativas ao consumo da população (COLOMBO, 2014), atividades e modalidades corporais investidas pelas academias de ginástica reiteram a primeira vertente que caracteriza esse negócio: seu caráter rentável, que atua na seleção (investimento) de práticas corporais do interesse público.

Em concomitância com a vertente acima, o gosto, teorizado por Bourdieu (2007), também representa conceito de equivalente valor explicativo. $\mathrm{O}$ autor, de forma contrária à ideologia segundo a qual os gostos são considerados um dom da natureza, estabelece, a partir de subsídios científicos, que as práticas culturais, como o ato de ler, a frequência a museus e concertos e as preferências por assuntos como educação, esporte, arte, mídia, entre outras, estão estreitamente vinculadas ao nível de instrução, estimado pelo diploma escolar ou pelo número de anos de estudo, bem como pela educação familiar. Em outros termos, gosto é produto do capital cultural adquirido na escola e herdado da família, e está atrelado à aptidão dos sujeitos em se apropriarem, de forma material ou simbólica, de objetos ou práticas marcadoras de sua posição de "classe" na sociedade (BOURDIEU, 1983, 2007).

Marcador privilegiado de "classe", conforme assevera Bourdieu (2007), o gosto, em sua visão, opera como disposição cultivada ao expressar a capacidade dos sujeitos em apropriarem-se, por meio de fontes educativas, das práticas culturais presentes na sociedade. Conforme Ollivier e Fridman (2001), o gosto também significa um conjunto de disposições e preferências livremente adotadas pelos atores sociais, refletindo a posição objetiva de classe que ocupam.

No campo das lutas, o mercado esportivo associado à estrutura social capitalista parece mascarar uma realidade: a oferta, pelas academias de ginástica, de modalidades de lutas hegemônicas no cenário do esporte-espetáculo e incorporadas, por hierarquia (DIMAGGIO, 1987), ao gosto da clientela. Em função 
disso, as academias vêm agindo por intermédio de um processo constante de observação dos gostos que, hierarquicamente, são prevalentes no grande público.

Portanto, rentabilidade comercial e gosto representam duas importantes bases explicativas colocadas em destaque no presente estudo, reveladoras do reconhecimento ou não reconhecimento da Luta Marajoara no âmbito das academias de ginástica investigadas de Belém-PA.

\section{Modalidades de lutas em academias de ginástica de Belém-PA: presenças e ausências}

Os dados produzidos nesta pesquisa, junto aos coordenadores e professores das academias investigadas, revelam que a inserção e permanência de modalidades de lutas nos referidos âmbitos estão atreladas, de modo acentuado, à demanda do público que frequenta esses espaços:

Pela procura, demanda [...]. Antes de eu vim pra cá, tinha um professor com poucos alunos na sala de Jiu-Jitsu [...]. Ele me entregou o horário faltando 15 dias para encerrarem o Jiu-Jitsu na academia, assim como se encerrou o Taekwondo. Só que em duas semanas eu consegui levantar. De um aluno eu consegui encaixar dentro da sala mais vinte (sic) (JJ2).

No relato supracitado, observa-se a lógica da demanda impregnada nas academias de ginástica, e o mesmo relato descreve, ainda, que o abandono do Taekwondo da lista de modalidades de lutas ofertadas, devido à inexistência de demanda de alunos, reforçou que atitude parecida ocorreria com outras modalidades ofertadas, caso a busca fosse igualmente inexpressiva.

Percebe-se, ademais, a questão do espaço físico e sua interferência no funcionamento e organização das práticas de lutas existentes nas academias de ginástica investigadas. Na visão gestora, esse critério incide na seleção, ausência ou permanência de modalidades de lutas nesses ambientes não formais: "Só tem um espaço, então, por mais que eu queira colocar, às vezes não tem horário [...] houve uma época em que o professor de lutas chegou a falar do Kickboxing, mas não tinha como encaixar, pois não havia horário disponível” (CO1).

Conforme revelado no relato, a insuficiência de espaços físicos e horários disponíveis impede que outras modalidades sejam incluídas. Com isso, o preenchimento das grades de horários está condicionado às lutas de maior aderência dos alunos-clientes e, por consequência, maior retorno financeiro.

No âmbito das academias de ginástica, o aluno não é meramente um aluno, mas sim um cliente; e o professor não é simplesmente um educador, mas também um vendedor (FURTADO, 2009). Há o interesse de se vender os benefícios das práticas de lutas ao aluno-cliente, um processo de compra e venda 
no qual o professor fica em segundo plano e seu conhecimento abaixo dos desejos dos clientes (SILVA; FREITAS; LÜDORF, 2019). As academias, portanto, possuem um contexto hierárquico no qual prevalecem os anseios do aluno-cliente e dos proprietários dos estabelecimentos. Contexto mais evidente aparece no estudo de Coelho Filho e Votre (2010), os quais ressaltam que a qualidade do trabalho do professor de Educação Física é avaliada pelo nível de aceitação do cliente.

$\mathrm{Na}$ escolha das modalidades de lutas ofertadas, cabe, ainda, pontuar sobre a participação dos professores. Nesse quesito, observam-se duas realidades. Na academia de pequeno porte, há maior flexibilidade e participação dos professores na escolha ou sugestão de modalidades possíveis de serem oferecidas ao público. Por exemplo, MT2 relata que "na verdade, eu posso participar se eu der a ideia [...]. Eles pedem que a gente dê. Por exemplo, semana passada, a coordenadora chegou para a gente e perguntou 'vocês têm ideia de alguma modalidade pro ano [...]?'”.

Contrariamente, na academia de grande porte, a participação é reduzida, uma vez que, por ser um espaço de franquia, as modalidades são escolhidas tendo em vista sua presença nas academias do grupo espalhadas pela cidade. Essa lógica é perceptível no relato de S1, "sempre teve Jiu-Jitsu na academia, então o que deu certo lá na outra unidade, a primeira unidade, eles trouxeram para cá”, em que se diminui a participação e a autonomia dos professores na escolha das modalidades, estando a administração central delegada a essa função.

O fato de o professor de lutas ter participação na seleção das modalidades remete a um cenário ideal para a ampliação da diversidade das práticas de lutas trabalhadas nas academias de ginástica investigadas. Nessa perspectiva, novas modalidades poderiam ser inseridas e, consequentemente, praticadas, a exemplo da Luta Marajoara.

Conforme analisado, o quadro a seguir apresenta, em forma de síntese, as implicações dos fatores associados à lógica rentável das academias da cidade de Belém-PA na oferta (ou não) da Luta Marajoara.

Quadro 2 - Lógica rentável no funcionamento de academias de ginástica e as implicações na oferta da Luta Marajoara.

Fatores Expressão nas academias de Belém-PA

Demanda

Espaço físico e materiais

Autonomia
Lutas de busca expressiva do público

Disponíveis às lutas com maior demanda Nenhuma ou pouca autonomia dos professores na
Implicações na oferta da Luta Marajoara

Baixa expressão e pouca demanda

Ausência de espaço e horário para prática

Não sugerida, portanto, não 
Fonte: Os autores.

Corroborando Furtado (2009), pode-se internamente observar que as academias de ginástica investigadas funcionam a partir de uma articulação comercial bem estabelecida pela procura-demanda e cliente-renda. Desse modo, conforme os relatos, a lógica rentável alinhada ao capitalismo-esportivo de funcionamento das academias influencia diretamente a seleção de lutas em seu interior. Ação igualmente influenciada por outros fatores, como espaço físico e participação profissional reduzida na sugestão e definição de novas modalidades. Tais fatores são capazes de implicar na ausência da modalidade Luta Marajoara nas academias pesquisadas.

\section{Reconhecimento da Luta Marajoara em academias: "gostos" e mercado esportivo}

A rentabilidade, como foi visto, parece determinar a escolha das modalidades de Lutas ofertadas ao público das academias investigadas nesta pesquisa. Com isso, a presença de determinadas modalidades perpassa, primeiramente, o aspecto de retorno financeiro viabilizado.

Esse aspecto é reforçado, nas academias, pelas justificativas assinaladas por seus coordenadores, as quais recaem nos fatores "demanda" e "viés comercial". CO2 assim ressalta: "[...] a montagem de grades [...] tem mais um viés comercial, são modalidades mais procuradas pelo público".

Por esse motivo, a lógica comercial e rentável das academias investigadas se conecta com a ausência constatada da Luta Marajoara e, portanto, seu ensino nesses espaços. Tal cenário parece apresentar duas recorrências: a) a oferta de modalidades de lutas rentáveis; e b) o não reconhecimento da Luta Marajoara como conhecimento e prática difundida ao público.

A ausência de reconhecimento do saber da Luta Marajoara, nas academias de Belém-PA pesquisadas, permite considerá-la prática corporal subordinada a outras modalidades de lutas e, nesse sentido, desprovida de identidade social legitimada. O pensamento de Taylor (2000) corrobora com a referida assertiva quando enfatiza que a ausência de reconhecimento incide na subordinação social e depreciação de determinados grupos sociais.

Ao associar o pensamento de Taylor (2000) à prática cultural histórica da Luta Marajoara, ocorre a atribuição de insignificância a essa luta, do ponto de vista de sua identidade social. Moldada pelo reconhecimento ou ausência dela, a identidade de grupos se constrói numa teia de relações democráticas que, na perspectiva do mesmo autor, mostra a necessidade das diferentes culturas serem compreendidas 
com base no seu valor e mérito social (TAYLOR, 1993). Uma vez não considerada para fins de oferta ao público, portanto, sucumbem o saber e reconhecimento da Luta Marajoara no interior das academias de ginástica.

Dessa forma, pode-se considerar que o pouco conhecimento da Luta Marajoara por alguns professores reitera sua fragilidade e desvantagem cultural em relação a outras lutas presentes nas academias: “[...] a fundo mesmo não conheço, [...] conheço bem mais uma arte lá de Israel, lá do outro lado do mundo, do que uma arte que é bem aqui do outro lado do rio" (MT2) ${ }^{3}$. Esse cenário se acentua quando a oferta depende, em grande medida, da demanda do próprio público frequentador, conforme visto anteriormente, ao passo que o interesse do aluno-cliente por uma modalidade de luta está associado intimamente ao conceito de gosto:

[...] depende da demanda. Vocês não vão ver chegar um cara e dizer: 'Ah, eu tô procurando a Luta Marajoara'. É muito difícil! As pessoas procuram mais o que é conhecido [...] A Luta Marajoara a gente não vê na televisão. Agora a gente vê o Wrestling, o Jiu-Jitsu, o Boxe, o Muay Thai. A pessoa procura aquilo que ela lembra que existe. Por exemplo, tu tá vendo TV e lembra que tem o Boxe: 'Ah, um dia vou fazer boxe. Vou entrar na academia aqui do lado de casa pra ver se tem o Boxe’. É assim que funciona. A luta marajoara não é tão conhecida [...] (sic) (JJ2).

A lembrança de existência de algo significa também disposição na busca por práticas que caracterizam o gosto dos indivíduos na sociedade. Mediante o exposto, com base nos dados analisados nas academias de Belém-PA, observou-se a existência de uma relação intrínseca entre gosto (atuando na preferência do público) e demanda (na perspectiva das academias, atuando na seleção das modalidades de lutas). De modo cíclico, essa lógica de funcionamento fortalece a não inclusão da Luta Marajoara nesses espaços.

\footnotetext{
${ }^{3}$ Parte do referido relato foi utilizada no título do manuscrito, dado o fato de representar um de seus resultados centrais, quer seja o pouco conhecimento da Luta Marajoara por professores e, com base nas análises, sua ausência em academias.
} 
Figura 1 - Relação gosto-demanda e influência na ausência da Luta Marajoara nas academias de ginástica de Belém-PA.

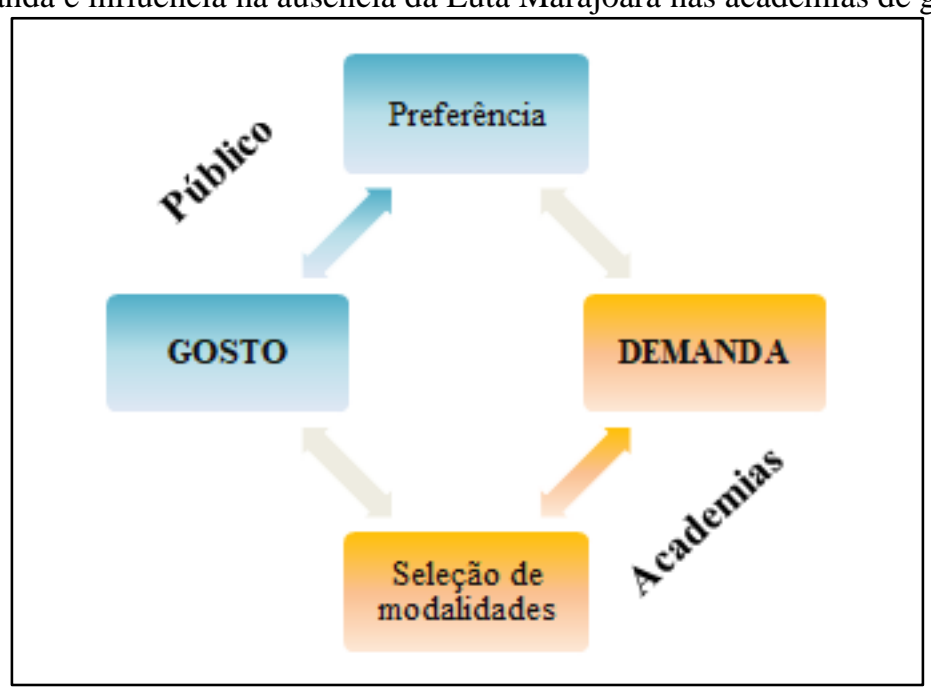

Fonte: Os autores.

As concepções de gosto de Bourdieu (2007), DiMaggio (1987) e as análises feitas por Ollivier e Fridman (2001) reforçam nossa discussão em alguns pontos.

Um deles compreende o argumento de DiMaggio (1987) acerca da variação dos gostos em função do tempo, lugar e condições históricas e sociais. Ao funcionarem acopladas a um sistema capitalista de mercado esportivo, as academias legitimam massivamente lutas que, em nosso tempo, exercem mais visibilidade do ponto de vista de sua repercussão social (CORREIA; FRANCHINI, 2010).

O fenômeno esportivo e sua consolidação na sociedade figuram como eventos de primeira ordem para a expansão capitalista de mercado. Nessa lógica, o esporte funciona enquanto uma cadeia produtiva, estabelecendo-se como mercadoria e abrangendo diversos segmentos de produção (COLOMBO, 2014).

Como fenômeno contemporâneo, os esportes de combate em academias, ao estarem associadas à espetacularização esportiva dos megaeventos (a exemplo do MMA), afirmam a lógica de expansão do capital nesse segmento. Primeiro, porque "nesses megaeventos esportivos, está presente a explicitação do mais alto nível do ponto de vista da tecnologia, da técnica, da tática, do desempenho, etc." (COLOMBO, 2014, p. 117). Segundo, porque o esporte-espetáculo possui grande potencial atrativo para investimento e consumo, conforme o autor.

Desse modo, situado na estrutura social capitalista, ao viabilizar em seu interior lutas em evidência nos megaeventos esportivos, como as praticadas nas Artes Marciais Mistas (MMA), as academias são influenciadas, ao mesmo tempo em que determinam o gosto do público por práticas culturais específicas (do esporte-espetáculo), organizando-as hierarquicamente no mercado esportivo das lutas. 
Outra questão mostra que o gosto caracteriza ponto de partida para o interesse público por determinadas modalidades de lutas existentes no cenário nacional ou internacional, as quais incorporadas (habitus) ao repertório pessoal e subjetivo dos indivíduos, por meio de condicionantes sociais externos, como a educação escolar e familiar ${ }^{4}$ (BOURDIEU, 2007). Assim, ao apropriar-se desse elemento categórico - o gosto -, as academias agem privilegiando certas lutas em detrimento de outras, tal como a Luta Marajoara. Embora pouco conhecida pelos sujeitos da pesquisa, essa luta ganhou evidência minimamente expressiva em decorrência da participação recente de lutadores marajoaras no MMA; representando, portanto, uma luta passível de incorporação ao gosto do público paraense.

Além disso, algumas percepções em relação à possível presença da Luta Marajoara nas academias foram acenadas. Dentre os argumentos, estão o desejo de sua presença por se tratar de uma luta regional, a não necessidade de materiais específicos para a prática e o fato de ser uma luta que despertaria a atenção do público por caracterizar uma novidade. Ao mesmo tempo, essa prática ainda precisa trilhar um caminho de conquista, por parte daqueles que desejam ter reconhecido seu valor em academias, na acepção tayloriana do termo.

[...] É conquista [...]. A Luta Marajoara, quem vir com ela, tem que vir com uma informação [...]. Que possa ajudar nisso, que possa ajudar naquilo. Tem que mostrar que ela vai melhorar o desenvolvimento da criança, que vai desenvolver um atleta que tá querendo fazer um MMA [...]. Eu acho que a Luta Marajoara tem que vir com força, tem que pegar uma galera e começar se apresentar, fazer treino no espaço público [...] (sic) (C1).

Conforme sugere $\mathrm{C} 1$, algumas tomadas de decisão são necessárias para um princípio de reconhecimento da Luta Marajoara, dentre as quais a organização de eventos públicos referentes à prática dessa luta. Nesse aspecto, sua difusão, ainda que mínima, seria facilitada, caso atitudes dessa ordem se maximizassem.

A regionalidade é outro fator favorável ao reconhecimento da Luta Marajoara. Se, na Educação Física escolar, o interesse por conteúdos culturais que dão evidência aos contextos locais e regionais (NEIRA, 2019) mostra-se um evento de vertente contemporânea, igualmente sua manifestação nos espaços não formais poderia ser impulsionada, dadas as finalidades educativas de ambos os espaços.

Em outra perspectiva, embora o aparecimento da Luta Marajoara nas academias seja uma aspiração por parte dos profissionais atuantes com as lutas, alguns entraves, na visão gestora, impedem

\footnotetext{
${ }^{4}$ A existência de outras fontes é possível. As academias, ao funcionarem como espaços de educação, representam lugares propícios à produção do gosto em relação às lutas. Em diálogo com Bourdieu (1983), a relação dos sujeitos com esses espaços e grupos neles inseridos definem seus gostos.
} 
que práticas com esta luta sejam organizadas. Espaço físico, materiais e descaracterização da luta foram os motivos levantados. Quanto ao último motivo, é revelado que:

[...] a Luta Marajoara, se a gente for trabalhar ela no tatame de forma comum, ela vai acabar sendo muito parecida com o Submission e a Luta Olímpica. Perde a característica. Então, a Luta Marajoara pode ser pelo nome, mas ela não vai ter todas as características [...] quando você tira o meio natural dela, que é a prática no terreno arenoso, ela acaba perdendo um pouco do seu sentido (CO2).

Em sua visão, a descaracterização da Luta Marajoara se manifestaria caso sua prática se dê em espaços de tatame, por exemplo. Duas argumentações são possíveis.

A primeira que, de fato, a Luta Marajoara perderia as características do ambiente em que são realizadas suas ações de movimento: a areia, principalmente. Entretanto, considerando as ações de comportamento técnico inerentes a sua prática (CAMPOS; PINHEIRO; GOUVEIA, 2019), a descaracterização relatada ocorreria de forma parcial, em virtude das possibilidades de estas serem realizadas no próprio tatame. O mesmo acontece com a capoeira, a qual, de forma característica, ambienta-se em espaços naturais e abertos, e cuja prática na academia de grande porte ocorre no tatame.

A segunda argumentação reside na organização dos espaços onde ocorrem as práticas em lutas nas academias. Concernente à Luta Marajoara, a construção de alternativas viáveis, considerando os espaços existentes para as aulas, representa ação de importante valor para esta luta.

Portanto, em se tratando das possibilidades para o princípio de reconhecimento, na acepção de Taylor (2000), de práticas da Luta Marajoara nas academias, algumas ações poderiam ser importantes:

a) Articulação das academias com praticantes e interessados para organização de eventos e difusão do conhecimento da luta.

b) Formação docente em Educação Física: lócus propício à socialização do saber elaborado da Luta Marajoara, no intuito de formar professores que abordem conhecimentos técnicos, culturais e teóricos.

c) Autonomia dos professores de lutas na seleção dos conteúdos ministrados nas academias: possibilidade de inserção de lutas menos conhecidas nesses ambientes.

d) Currículo da escola básica: segundo Bourdieu (2007), a educação escolar possui um papel elementar na produção do gosto. A Educação Física escolar precisaria tematizar a Luta Marajoara, de modo a desestimular seu esquecimento e incorporá-la ao rol de modalidades de 
lutas do gosto público, na concepção bourdieusiana do termo, facilitando sua entrada nos mais diferentes espaços sociais.

\section{Considerações finais}

Este artigo objetivou compreender o reconhecimento da Luta Marajoara a partir da análise da lógica de funcionamento de academias de ginástica. Foram investigados trinta estabelecimentos localizados na cidade de Belém-PA, sendo que, em dois, foram entrevistados professores de lutas e coordenadores.

Conforme investigado, observou-se que a condição para seleção das modalidades de lutas nas academias de Belém-PA depende, essencialmente, da demanda oriunda dos clientes e, secundariamente, da sugestão e definição compartilhada de novas modalidades entre professores e gestores. Dessa forma, a lógica em tela implica diretamente o não reconhecimento da Luta Marajoara.

Outro fator explicativo para o não reconhecimento da Luta Marajoara, em academias de ginástica na cidade de Belém-PA, diz respeito ao conceito de gosto, teorizado por Pierre Bourdieu. O gosto por práticas de lutas mais reconhecidas no mercado esportivo pode ser determinante para o esquecimento de outras modalidades distantes desse contexto.

Apesar disso, alguns fatores podem atuar favoravelmente em direção ao reconhecimento da Luta Marajoara nas academias investigadas, como sua natureza regional; a não necessidade de materiais específicos para prática; e o fato de despertar o interesse do público por ser uma modalidade de luta nova. Aliado a esses fatores, a organização de eventos para difusão da Luta Marajoara, a formação e autonomia profissional, bem como a educação escolar exercem papel imprescindível.

Por fim, as reflexões apresentadas nesta pesquisa representam os primeiros passos no longo trajeto a ser percorrido para o reconhecimento do saber e prática da Luta Marajoara seja no âmbito não formal das academias de ginástica ou em outros ambientes de relevância social, educativa e formativa. Esforços outros precisam ser empreendidos, a fim de que esta luta "do outro lado do rio" seja descoberta, valorizada e tenha sua identidade reconhecida, tal qual as artes "do outro lado do mundo". 


\section{Referências}

BOURDIEU, Pierre. A distinção: crítica social do julgamento. Tradução Daniela Kern; Guilherme João Freitas Teixeira. 1. ed. São Paulo: Edusp; Porto Alegre, RS: Zouk, 2007. 560 p.

BOURDIEU, Pierre. Gostos de classe e estilos de vida. In: ORTIZ, Renato. (Org.) Bourdieu Sociologia. 1. ed. São Paulo: Ática, 1983. p. 82-121. (Coleção Grandes Cientistas Sociais).

CAMPOS, Ítalo Sérgio; PINHEIRO, Claudio, J. B.; GOUVEIA, Amauri. Modelagem do comportamento técnico da Luta Marajoara: do desempenho ao educacional. Revista Brasileira de Ciência e Movimento, Brasília, v. 27, n. 2, p. 209-217, 2019.

COELHO FILHO, Carlos Alberto de Andrade; VOTRE, Sebastião Josué. Imagens da prática profissional em academias de ginástica na cidade do Rio de Janeiro. Revista Brasileira de Ciências do Esporte, Campinas, v. 31, n. 3, p. 95-110, 2010.

COLOMBO, Bruno Dandolini. O esporte e a expansão do capital: as críticas, contradições e implicações para a Educação Física. 2014. 125 f. Dissertação (Mestrado em Educação) - Centro de Ciências da Educação, Universidade Federal de Santa Catarina, Florianópolis, SC, 2014.

CORREIA, Walter Roberto; FRANCHINI, Emerson. Produção acadêmica em lutas, artes marciais e esportes de combate. Motriz, Rio Claro, v. 16, n. 1, p. 01-09, jan./mar. 2010.

DIMAGGIO, Paul. Classification in art. American Sociological Review, New York, v. 52, n. 4, p. 440$455,1987$.

FREITAS, Rogério Gonçalves de; OLIVEIRA, Marcos Renan Freitas de; COELHO, Higson, Rodrigues. Recentes Diretrizes Curriculares Nacionais dos cursos de graduação em educação física e disruptura na formação: apontamentos preliminares. Caderno de Educação Física e Esporte, Marechal Cândido Rondon, v. 17, n. 1, p. 245-253, jan./jun. 2019.

FURTADO, Roberto Pereira. Do fitness ao wellnes: os três estágios de desenvolvimento das academias de ginástica. Pensar a Prática, Goiânia, v. 12, n. 1, p. 1-11, jan./abr. 2009.

GIL, Antonio Carlos. Métodos e técnicas de pesquisa social. 6. ed. São Paulo: Atlas, 2008.

MINAYO, Maria Cecília de Souza. Técnicas de pesquisa: entrevista como técnica privilegiada de comunicação. In: LOBIONDO-WOOD, Geri. O desafio do conhecimento: pesquisa qualitativa em saúde. 12. ed. São Paulo: Hucitec, 2010. p. 261-297.

NEIRA, Marcos Garcia. Educação física cultural: inspiração e prática pedagógica. 2. ed. Jundiaí, SP: Paco, 2019.

OLLIVIER, Michèle; FRIDMAN, Viviana. Taste and taste culture. In: SMELSER, Neil J.; Baltes, Paul. B. (Eds.). International Encyclopedia of the Social and Behavioral Sciences. 1. ed. Oxford: Pergamon, 2001. p. 15442-15447. 
SANTOS, Carlos Afonso Ferreira dos; FREITAS, Rogério Gonçalves de. Luta marajoara e memória: práticas "esquecidas" na educação física escolar em Soure-Marajó. Caderno de Educação Física e Esporte, Marechal Cândido Rondon, v. 16, n. 1, p. 57-67, jan./jun. 2018.

SANTOS, Carlos Afonso Ferreira dos; GOMES, Ivan Carlo Rego; FREITAS, Rogério Gonçalves de. Luta Marajoara: lugar ou não lugar no currículo de uma IES pública do Estado do Pará. Motrivivência, Florianópolis, v. 32, n. 61, p. 01-24, jan./mar. 2020.

SILVA, Alan Camargo; FREITAS, Diego Costa; LÜDORF, Silvia Maria Agatti. Profissionais de Educação Física de academias de ginástica do Rio de Janeiro e a pluralidade de concepções de corpo. Revista Brasileira de Ciências do Esporte, Campinas, v. 41, n. 1, p. 102-108, 2019.

TAYLOR, Charles. A política do reconhecimento. In: TAYLOR, Charles. Argumentos filosóficos. 2. ed. São Paulo: Edições Loyola, 2000. p. 241-274.

TAYLOR, Charles. La política del reconocimiento. In: TAYLOR, Charles. El multiculturalismo y la política del reconocimiento. Tradução de Mónica Utrilla de Neira. México: Fondo de Cultura Económica, 1993. p. 43-107.

\section{Como citar este artigo}

SANTOS, C. A. F.; ANDRADE, W. A. G., FREITAS, R. G. "Conheço bem mais uma arte do outro lado do mundo que uma aqui do outro lado do rio": luta marajoara e reconhecimento em academias de ginástica. Revista Kinesis, Santa Maria, v. 39, p.01-15, 2021.

* O presente trabalho não contou com apoio financeiro de nenhuma natureza para sua realização 